\title{
A CRITICAL REVIEW DEMENTIA IN MIDDLE AGE
}

BY

\section{W. H. MGMENEMEY}

\section{Introduction}

WHEN a middle-aged person is presented for examination because of symptoms of developing dementia, the physician is faced with an interesting, and often an exacting, problem in differential diagnosis. It is proposed to discuss the causes of progressive dementia in such persons and at the same time to make observations from the clinical and pathological viewpoints concerning the individuality of certain of these diseases.

\section{The Import of " Presenile Dementia"}

The use of the word " presenile" as applied to dementia does not connote a senile ætiology but merely a period of life. Nevertheless, partly, no doubt, because of the similarity of the histologies of Alzheimer's disease and senile dementia, the term appears to be regarded by not a few in a way which presupposes senescence as an ætiological factor: thus, such patients are sometimes said to be "suffering from senility before their time." This not uncommon misapprehension tends not only to segregate these diseases (" the essential dementias of the presenium "), of which the age incidence is characteristically in the presenium, but also to obscure their true place in the hegemony of neurological disorders. How far, in point of fact, senescence is implicated in these diseases remains to be seen.

The presenium or middle age is usually understood to include the years from forty to sixty, but some would extend the upper age limit to sixty-five. One is aware, however, of differences in ageing as seen in various individuals and families: some persons are senescent by sixty whilst others are still middleaged in body and mind when they have reached "the allotted span." The saying that a man is as old as his arteries is a generalization which finds some confirmation in the histology of the ageing brain. That years alone do not age a man is well exemplified in that extreme instance of precocious senescence to be found in progeria: such subjects may be senile, in all respects, in childhood. The presenium and senium are but arbitrary epochs and no hard and fast dividing line can be made between them. It was the desire to distinguish between Alzheimer's disease and senile dementia which led to the specialized conception of the presenium. 
A careful study of the patient's history and present condition, together with cursory acquaintance with the immediate relatives, will suffice to show whether he or she has entered the senile period of life. The essence of a presenile dementia, if the term is to have any significance at all, is that the mental illness has begun at a time when the patient still retains normal vitality of body and mind.

It is unfortunate that the term " presenile dementia" has, for some people, come to be but a synonym for Alzheimer's disease or Pick's disease, for there are many other causes of dementia in middle-aged subjects. Reviews on " presenile dementia" have been made by Kehrer (1925), Runge (1930), and by Schottky (1932). In recent years, also, there have been two discussions at the Royal Society of Medicine (Critchley et al, 1933; Mayer-Gross et al, 1938) which have served to indicate the scope of this concept of " presenile dementia," but Critchley at the outset stressed the fact that for the neurologist it usually offered itself as a problem in differential diagnosis. The first discussion provided an excellent account of the "essential presenile dementias," while the second, although largely confined to a psychiatric analysis of the symptomatology, did give a further and clear reminder of the variety of diseases to be met with in this group.

It is clear, therefore, that the term "presenile dementia " can have only a clinical meaning for provisional use while the diagnosis is as yet unsettled, and that when a patient in this age-group presents symptoms of intellectual deterioration the temptation to label the case as one of the essential dementias of the presenium should be resisted until all the other theoretical causes have been reviewed; only in this way is it possible to avoid overlooking a cerebral tumour with unusual symptoms and signs.

It has been suggested that the presenile group of dementias be divided up into two, primary and secondary; the latter includes those of known ætiology -for example, tumour, syphilis, or arteriosclerosis-while the former category is reserved for the diseases of uncertain ætiology. Such a classification, although based upon our present state of ignorance, appears to be the only one possible at present.

It has been customary to retain the use of the term " presenile dementia" for the small numbers of cases which owe their origin neither to tumour, trauma, infections, nor arterial disease, but which are the "primary" or " essential" dementias of the presenium. These diseases, which are of particular interest, are generally believed to be rare, for they are infrequently reported and their nature is at present imperfectly understood. Being placed between the well-defined insanity of adolescence and the familiar dementias of old age, and being readily confused with other involutional psychoses, these maladies often pass unrecognized during life whilst they are overlooked not infrequently at autopsy.

Dementia implies a disturbance of function of the cortical cells of the brain, although in not a few instances subcortical or other cells may be primarily responsible for the symptoms (Putnam, 1939). This disturbance of function may, or may not, be accompanied by a morphological alteration of the cells. 
The earliest signs of dementia vary little, whatever be the underlying pathological cause: they amount to an alteration in the personality, so that the patient's friends notice in him a certain lack of initiative, or maybe an irascibility, a facileness or a lack of interest which is foreign to his nature. His mood will be determined largely by his previous personality, but in general it has been said that presenile dementias are characterized by depression rather than excitement. A paranoid trend may be detected as an early symptom in one who has shown this pattern in his previous psychological make-up. As the disease develops it soon becomes apparent that the mind is being deranged concurrently in cognitive, affective, and conative aspects. The attention becomes readily distractable, and the patient develops a memory defect, at first for recent happenings, and this may show itself as forgetfulness when writing (missing of letters and words), or as a disorientation in time or even place, becoming more and more noticeable as the illness progresses. The disordered action of the mind, and especially the disturbed effect, may find expression in conduct which lacks the control of reason, so that perseveration, stereotopies, and verbigeration may be prominent symptoms. Although the amount and type of motor unrest which may characterize a presenile dementia vary considerably in different cases, some degree is to be expected in most, and an explanation has been offered for this fact by postulating that this activity is but the expression of the victim's reaction to the abnormal state of his brain. The final stage of dementia is one of complete apathy, intellectual dullness, failure of all memory, and loss of sphincter control. The march of dementia has this general pattern irrespective of the determining pathology. Nevertheless, some dementing diseases have symptomatologies which are more or less characteristic and are of help in diagnosis. The early stage of dementia may be readily obscured by, and sometimes simulated by, the confusion which accompanies a severe toxæmia, by dysarthria, paraphasia, or mutism.

The diseases which may manifest themselves in middle age and give rise to symptoms of dementia are many. In not all of them does the dementia become profound. In reviewing the causes of "presenile dementia" it is convenient to consider first the so-called " primary" group.

\section{So-called Essential Dementias of the Presenile Age-group}

There are two diseases associated with the names of Alzheimer and Pick respectively which are usually regarded as constituting this group. Sometimes, however, the term "presenile dementia" has been used as a synonym for Alzheimer's disease.

Alzheimer's disease.-The recognition of this condition dates from 1907, when Alzheimer described it for the first time. Since then some hundred or more instances of the disease have been reported, but probably very many more have been overlooked whilst not a few have been recognized but not reported. It seems likely, in point of fact, that the disease is not uncommon. Histologically, there are changes of the type seen in senile dementia, but they are more severe. Thought at one time by Fuller (1912) to be but a senium præcox, the 
revolt against this view was led by Barrett as long ago as 1913 as the result of a critical histological analysis of a case dying at the age of thirty-one. Since then other examples of the disease have been described in persons under the age of forty, and Lowenberg and Rothschild (1931) have recorded the case of a woman who, several years after the beginning of the illness, gave birth to a healthy child. Although it is classically a disease of middle age and onwards somatic manifestations of senility are rarely present. On the contrary, Malamud and Lowenberg (1929) have described an example commencing at the age of seven, after scarlet fever, and proving fatal within sixteen years. At autopsy, the histological findings were typical of Alzheimer's disease, but, in addition, there were extensive degenerative processes in the choroid plexus. Their conclusion is that, ætiologically, the clinicopathological syndrome which we know by the name of Alzheimer's disease may be caused by a variety of factors. We are, as yet, entirely in the dark as to the nature of these; we conjecture that they are toxic or degenerative in origin, producing results in the cerebral parenchyma similar to those which we associate with a type of dementia found in the elderly. The impression is gained in examining cases of Alzheimer's disease histologically that some of them are in keeping with what Fuller called " senium præcox," whereas others suggest the visitation of some cataclysmic agent, so great is the extent of the process: these two extremes may approximate to the intrinsic and extrinsic forms of the disease which we believe exist.

There are certain examples of the disease which have shown a familial character (Lowenberg and Waggoner 1934; McMenemey, Worster-Drought, Flind and Williams, 1939). The first of these concerned a father and four out of his five children. The other instance was a man, in the previous generation of whose family three out of four siblings were afflicted with a similar disease. In both of these studies it came to light that there had been first cousin marriages in the parents. It should be added that the evidence for the familiar character in these cases is circumstantial, as in each instance the brain of only one afflicted member of the family has been examined histologically. It is certain, however, that the clinical illnesses were always similar, and there is a record of an incomplete examination of a brain in one member of the family described by Lowenberg and Waggoner which is highly suggestive of Alzheimer's disease. Schottky's (1932) family with presenile dementia may have been an instance of Alzheimer's disease, although the author favoured the diagnosis of Pick's disease: only the naked eye findings are mentioned. In addition, there are other examples where a family history is suggestive (von Braunmuhl, 1932; Rothschild, 1934), whilst Lowenberg (1937) quoted an example of a man with Alzheimer's disease whose father had had senile dementia. In view of the anatomical similarity of these diseases it should be mentioned that Meggendorfer (1926) and Weinberger (1926) both believe that heredity plays some part in senile dementia, but Grunthal (1936) maintains that nothing concrete can be established on this score. The late age of onset of senile dementia must, of necessity, make it difficult to obtain a family history. It has, however, been described in twins (Scheele, 1933).

It would seem premature to press for an heredodegenerative outlook 
on Alzheimer's disease in view of the relatively few reported instances of a familial incidence, but it seems not improbable that some cases owe their origin to an abiotrophic tendency sufficiently definite to be brought into play by a minimum of extrinsic influences. The reported examples of this disease occurring under the age of forty (Perusini, 1910; Barrett, 1913; Urechia and Danetz, 1924; Malamud and Lowenberg, 1929; Struwe, 1929; Schottky, 1932; Kufs, 1937) are more readily explained in this way. The last of these cases had, in addition to the characteristic findings of Alzheimer's disease, sclerosis of the olivary bodies and atrophy of the basal ganglia, findings not easy to explain unless the abiotrophic view is accepted.

It would seem best to regard Alzheimer's disease as a psychosis of middle age which has a histological picture similar to but usually more extensive and severe than that of senile dementia. The last word remains to be said on the relationship of these diseases to one another. Wilson (1940) would group them together, regarding the pathological arrangement as preferable to the clinical. Whilst it is difficult to exclude senility as a factor in the ætiology of senile dementia, it is worth a thought that there are other senile psychoses, as, for instance, the type described by Claude and Lhermitte (1910), which lack the recognized histology of senile dementia: in many cases of Alzheimer's disease, however, it appears equally improbable that senility could be reckoned as a factor in ætiology, although abiotrophy or " premature local decay" could be accepted without cavil. The Růžička-Grünthal biological hypothesis, however, to which reference is made later, allows of both extraneous toxic factors and either senility or abiotrophy being concerned.

Clinically, we know Alzheimer's disease as a progressive dementia with a course, on the average, of from two to five years, occurring typically in persons between the ages of forty and sixty and usually in the absence of arterial disease. There is nothing unusual about the dementia except that eventually it becomes profound and is usually associated with emaciation. It is preceded by a characteristic phase of great excitement, restlessness, and confusion. Rothschild and Kasanin (1936) have described the reactive symptoms as "an attempt at rejuvenescence in face of an abnormal ageing process." There may be involvement of either the pyramidal or extrapyramidal motor system, or both, and epilepsy is not unusual, especially late in the course of the illness. Loss of memory for recent events is not infrequently the first symptom which brings the patient to the physician's notice. According to Boyd (1936) the early intellectual failure which characterizes this condition is more in the nature of a loss of co-ordinating function and a narrowing of the ability to perform in several fields at once. When it is recalled how widespread are the histological changes it is not surprising that the dementia becomes extreme; neither is it unexpected that the symptomatology can vary, depending upon the march of the process; in some cases, for instance, aphasia may be an early and prominent sign. Occasionally the disease appears to become arrested. Sometimes focal symptoms are marked, and at autopsy the atrophy may be so unevenly distributed as to suggest Pick's disease.

The characteristic histological picture, apart from atrophy of the nerve 
cells, is the presence of " senile plaques" in great numbers and of the " neurofibrillary change of Alzheimer." Neither of these findings is pathognomonic, and authenticated instances of the disease are known in which plaques alone were present: Alzheimer himself published a case of this nature, the distinguishing feature being the presence of large plaques. Senile plaques, therefore, are invariably present in this malady, and if the case is long-standing they may be very numerous. They are found in the grey matter of the cortex, especially in the second and third laminæ of the frontal and occipital regions and of the hippocampus. They are less plentiful in the pre- and post-central gyri. They may be found in the basal ganglia and cerebellum. In oldstanding cases the cortical grey matter may be almost entirely occupied by these curious structures. They are recognized in silver impregnated sections as irregular-shaped masses measuring up to $100 \mu$ in diameter; around the dark centre, which may give the chemical reactions for amyloid, are numerous clublike masses radiating outwards and bearing a superficial resemblance to actinomyces. With suitable modifications of the silver technique microglial cells can be demonstrated in the substance of the plaque, and farther out in the periphery lie astrocytes which have largely undergone fibrous transformation. Von Braunmühl (1932) believes their origin to lie in a densification of the ground substance. This, again, is in keeping with the hypothesis of Rưžička $(1922,1924)$ who maintains that, with advancing years, or on account of illness, there is a tendency for the colloids of the body to aggregate into larger particles and to precipitate out. To this phenomenon the name of " protoplasmahysteresis " is given, and it represents the third biological process, the other two being assimilation and dissimilation. The senile plaque does not appear, as yet, to have been described in animals. There are, however, certain other structures met with from time to time which resemble senile plaques. A case described by Gerstmann, Straüssler, and Scheinker (1936) concerned a twentysix-year-old female who died of a cerebellospinal degeneration which had been transmitted as a dominant through several generations. At autopsy curious incrustations were found in the cortex, especially in the superficial layers, the basal ganglia, and the white matter, which had some resemblance to senile plaques. They are figured as being numerous in the molecular layer of the cerebellum. Their distribution is unusual for senile plaques, and certainly they seem to differ from these in several respects. In addition there are the socalled fatty plaques, which have been described also in animals (Rizzo, 1924) and various "metabolic" and "myelin" bodies which have been reported in adult forms of Schilder's disease. Yet another type of "pseudoplaque" was seen in an unusual familial presenile dementia reported by Worster-Drought, Greenfield, and McMenemey (1940); these structures were mostly in relation to blood vessels.

The second histological feature of Alzheimer's disease is the presence of irregularly thickened neurofibrils, usually bent and twisted so as to justify the use of the terms " tangles" and "loops." Recent studies by Alexander and Looney (1938) suggest that these structures are " hypermineralized." Although characteristic they may be scanty or even absent, but as a rule they constitute 
a striking feature of the histology. Bouman (1934) regarded this change as an example of "hyperdifferentiation" similar to that which may occur after injury. Although the thickened neurofibril may represent an attempt at healing there is every reason to hold that any such attempt fails in its purpose. It is impossible to believe that a nerve cell showing such a change in the structure of its neurofibrils, even making allowances for the fact that the change which we see is in autopsy or biopsy material after fixation and impregnation, can be able to function in its usual way, and one presumes that such a cell is already effete. Bouman's theory was applicable to all the changes seen in this disease and in senile dementia, namely senile plaques, "torpedoes," and dendritic swellings. It would seem right to regard them as all of the same order and the Rưžička-Grünthal hypothesis can be applied as readily to the neurofibrillary change as to the senile plaque. The latter concerns the "ground substance" whereas the former implies a more devastating process involving the nerve cells as well. This explanation will account for the fact that the senile plaque is characteristic of senile dementia whereas the neurofibrillary change is most familiar in Alzheimer's disease (Critchley, 1930), and also for the fact that although plaques not infrequently occur in the absence of the alteration in the neurofibrils the converse is probably unusual, if not unknown. It presupposes a greater likelihood of the impoverished ground substance being first concerned in the more benign senile dementia, whereas in the younger subject the highly organized neurone succumbs first to the more malignant Alzheimer's disease.

Although both the plaques, and more especially the neurofibrillary alterations, are less numerous in senile dementia, Grünthal (1930) has stressed the fact that in some cases it may be impossible to tell the two diseases apart. Indeed it may well be that the differences both in symptomatology and histology between these two diseases may be no more than can be accounted for by the fact that in Alzheimer's disease the patient is younger and therefore better able to resist the onset of the illness. In Alzheimer's disease there is a rough parallelism between the number of plaques and neurofibrillary alterations; but a quantitative estimation of the former is no true guide to the severity of the symptoms although it is some index of the duration of the disease. If the neurofibrillary alterations are much in excess of the senile plaques it suggests that the illness is of relatively short duration and that it is a malignant form.

Although the association of senile plaques and neurofibrillary alterations in a presenile subject is strong evidence of Alzheimer's disease, Rothschild and Kasanin (1936) insist that, before the diagnosis can be established, the clinical findings must also be typical. These authors have described examples of toxic psychosis with the histological characteristics of Alzheimer's disease which they are not prepared to accept as instances of the latter. It would seem feasible, however, to regard such cases as instances of Alzheimer's disease which have been precipitated by reason of an acute illness. Such cases, in fact, approximate more to the "extrinsic" type of case than to the "intrinsic" or "pure" abiotrophic variety.

Neuburger and Braunmühl (1930) instance a man of fifty-six with a traumatic 
dementia dating back to the age of twenty-two whose brain showed an abundance of senile plaques. More recently Claude and Cuel (1939) have described the case of a female who died of a dementia, at the age of fifty-seven, seven years after an accident. Histologically the lesions are said to be typical of " senile dementia" with both senile plaques and neurofibrillary alterations. These cases furnish a useful illustration of the frequent co-existence of both abiotrophic tendency and external precipitating factors in the ætiology of this disease.

Vascular alterations in Alzheimer's disease are minimal and are not thought to play any part in its ætiology, although Krapf (1931) has suggested that arterial hypertension requires consideration, especially as a factor predisposing to epileptiform seizures.

Pick's disease.-This term is confusing because it is also applied to polyorrhomenitis; for this reason Nichols and Weigner (1938) prefer to call it " idiopathic circumscribed presenile cerebral atrophy," a comprehensive title which succeeds in describing an average case. It affects principally women between the ages of fifty and sixty, the course of the illness being from two to ten years. It was first described by Pick in 1892, since when some seventy examples have been recorded, the youngest of whom was only twenty-one (Lowenberg, Boyd, and Salon, 1939). It is probably rarer than Alzheimer's disease. Nichols and Weigner (1938), however, believe it to be commoner than is suggested by the number of recorded cases. This view is almost certainly correct, for until recently the only examples reported have been those with frank atrophy of some part of the brain; it seems likely, however, that instances not infrequently occur without much naked eye evidence of atrophy: one such was reported by Bouton (1940).

The atrophy concerns certain of the cortical cells, especially the upper three layers, but Freeman (1933) believes that the process begins in the white matter. Usually the frontal lobes are affected, but occasionally the temporal poles and less often the parietal lobes, are involved. Sometimes a whole hemisphere shares in the atrophy, including the subcortical white matter. Moreover, some authors have noted the involvement of several lobes, or even both hemispheres, whilst others have found the basal ganglia and substantia nigra implicated in the atrophy. It is said that the left side of the brain is involved more often than the right, and this may account for the fact that aphasia is a frequent symptom. The atrophy, therefore, although usually circumscribed may affect practically any part of the brain, and Ferraro and Jervis (1936) stress the fact that histological changes, although most in evidence in the grossly atrophic areas, are diffuse throughout the whole cortex. This observation is in keeping with the clinical description of this disease given by Goldstein and Katz (1937) as a " systemic deterioration of the function of the cortex of the brain." Bouton (1940) remarks on the close proximity of apparently normal cells to those in an advanced stage of chromatolysis even in the most affected areas. Gliosis follows the atrophy, so that the "varying course of the disease is faithfully reflected in the condition of the glial elements" (Bouton). According to Davison (1938) no specific cortical laminæ are concerned in this 
disease. Urechia (1930) considers the presence of argentophil corpuscles in the basal parts of the nerve cells to be almost pathognomonic of this disease.

Early symptoms are amnesia, aphasia, akinesia, and a gradual loss of control of the higher cerebral functions. When the frontal lobes are involved the dementia is progressive and eventually profound, although the loss of memory is seldom complete. According to Bouton (1940), however, careful examination will often elicit the fact that the memory is surprisingly intact at a time when it would appear, on less critical examination, to be much impaired. Malamud and Boyd (1940), in discussing atrophy of the temporal lobe in this disease, remark on the type of mental deterioration to be expected: according to these authors it amounts to a reduction in associative power and thinking, in judgment and insight, whereas memory, orientation, and attention remain relatively preserved for some time. Benedek and Lehoczky (1939) find that even if there is severe deterioration of the mind there remains an emotional accessibility. Similar observations have been made by Stertz (1926), Schreider (1927), and von Braunmühl and Leonhard (1934). Goldstein and Katz (1937) comment on the preservation of the active abstract attitude in behaviour. They recommend a critical psychological examination at the stage of the disease when personality has not yet been changed to such a degree that good co-operation and an exact examination are impossible. Schenk (1938) speaks of the importance of a knowledge of the prepsychotic personality in studying these cases. As insight is usually impaired early on in this disease it forms a useful diagnostic point from cerebral arteriosclerosis. There is considerable individual variation in the symptomatology and the duration of the illness, depending, no doubt, upon the site of the atrophy, but the following differential points are usually given to distinguish it clinically from Alzheimer's disease. The age of onset tends to be later, the course is more protracted, epilepsy is rare, and the patient is apathetic and totally lacking in initiative, whereas in the latter disease restlessness is characteristic at some stage in its course. On the other hand, some authors have described a preliminary phase of restlessness in Pick's disease which in some cases appears to have been marked. Nichols and Weigner (1938) notice a resemblance between Pick's disease and general paralysis paralleled by the similarity of Alzheimer's disease to senile dementia.

The ætiology is till doubtful. Gans (1922) was inclined to place this disease in the category of the abiotrophies, because the parts of the brain involved are phylogenetically young. Orari and Spatz (1926), Ferraro and Jervis (1936), and Davison (1938) have disagreed with this assertion of Gans, because the areas concerned have not always been phylogenetically the youngest. On the other hand, Shenk supports the view of Gans. The occurrence of this disease in families appears to strengthen the abiotrophic view and the very nature of the malady is in keeping with our conception of heredodegeneration. Benedek and Lehoczky (1939), in fact, consider that the importance of familial factors in Pick's disease may be taken as satisfactorily established. In a case described by Thorpe (1932) there was a history of the father having had senile dementia. Grünthal (1922), Braunmühl and Leonhard (1934) and Shenk (1938) have described undoubted familial instances of this 
disease and there are others in the literature which, according to Ferraro and Jervis (1936), have not been sufficiently proved. The latter authors do not, however, favour classifying this disease as a member of the heredodegenerative group, and therefore independent of senility, on the grounds that the number of observations is not as yet sufficient to warrant this opinion. They prefer to regard it, with Pick, as a senile process. Although they found only slight vascular changes they noticed an extensive perivascular distribution of the disease, and they postulate repeated localized vascular spasm as the cause of the circumscribed atrophy; they conclude, however, by stating that they are not prepared to say whether angiospasm may more easily affect a predisposed tissue. Davison (1938) found some confirmation for this view in a histological study of his first case. The smaller cortical vessels were frankly sclerotic, but as the patient was sixty-three years of age it is not unlikely that the association was fortuitous. Without in any way detracting from the theory of angiospasm postulated by Ferraro and Jervis (1936), one must admit that the cerebral vessels in this disease appear from a study of the literature to have been singularly free from histological evidence of disease. Moreover, the sex incidence of Pick's disease (and for that matter of Alzheimer's disease also) is the opposite of that of cerebral arteriosclerosis (Rothschild, 1938). It would appear, therefore, that the exact nature of this disease is still obscure, but that reliable evidence exists for regarding it as a heredodegeneration.

With regard to more recent diagnostic procedures, encephalography or ventriculography may furnish good evidence of organic dementia, and the diagnosis of Alzheimer's and Pick's diseases may be placed on a firmer basis on their account. It is important to recall the fact, however, that cases of Pick's disease may lack gross atrophy whilst there are instances of Alzheimer's disease revealing themselves in so focal a way as to suggest the other. Both these disorders, and especially Alzheimer's dementia, may be diagnosed for certain by biopsy, and there is often justification for this measure, for it may also serve to establish or exclude the presence of other maladies. Angiography has been employed in the recognition of Pick's disease.

\section{Certain Degenerative Conditions of the Brain associated with Dementia}

Huntington's chorea.-In some reported instances the dementia, which may be regarded as an integral part of this disease, has preceded the choreiform movements, and occasionally the illness has run its course without any hyperkinesis, other afflicted members of the families showing the disease in a more typical form (Davenport and Muncey, 1916; Worster-Drought and Allen, 1929). Davenport and Muncey say “. . . there are among the children of typical choreics so many cases of dementia without choreic movements as to warrant the hypothesis that the dementing factor in a choreic strain may be inherited independently of the other symptoms." In a recent study of six cases, Stone and Falstein (1938) show that the atrophic process involves the brain as a whole and that the frontal and precentral parts especially are involved, particularly the ganglion cells of the third and fourth laminæ. As long ago as 
1911, Alzheimer had stated that there could " hardly be a remaining doubt" that in Huntington's chorea severe degenerative processes were regularly present in the cerebral cortex. Dunlap (1927), in his classical paper on the subject, remarked that in pure and well-developed instances of the disease there were constant lesions present in the cerebral cortex as well as in the corpus striatum, but he admitted that to date he had been unable to convince himself that there was any true loss of cortical cells.

Minski and Guttmann (1938) remark that it does not seem possible to distinguish the dementia of Huntington's chorea from that in other types of dementing psychosis by any one specific feature such as a characteristic disturbance of thought. They note, however, that the most common mood seems to be one of indolence and apathy.

The so-called "Creutzfeldt-Jakob disease."-This condition was first described by Creutzfeldt in 1920 and later by Jakob in 1921. Some fourteen or more cases have so far been recorded which approximate to this disease, but there is still much uncertainty as to its entity. The changes are widespread and affect the basal ganglia and the deeper layers of the cerebral cortex, giving rise to partial degeneration of the pyramidal and extrapyramidal pathways. The disease, in its early stages, is said to be mistaken occasionally for disseminated sclerosis. The course varies from a few months to a couple of years, and the most usual age of onset has been in the fourth and fifth decades.

The symptomatology has been reviewed fully by Jansen and MonradKrohn (1937). There is a prodromal or " neurasthenic" stage of the illness which may last a few weeks or months. Slight alterations in temperament and memory may be noticed by the patient's friends, and complaint is made of weakness of the limbs, unsteadiness of gait, and insomnia. The malady develops in a subacute fashion into an "organic" stage in which neurological disturbances are widespread. There may be nystagmus, dysarthria, and ataxia. The limbs become spastic, with exaggeration of the deep reflexes and usually extensor plantar responses. Choreoathetoid movements may occur, but sensory changes are not evident, although complaint may be made of pains in the limbs. The psychical alterations represent a relentless march to a stage of profound dementia, and the earlier symptoms are no doubt determined by the patient's prepsychotic personality: thus there may be excitement, depression, or negativism. There is a tendency to confabulation, whilst delusions and hallucinations have been noted. Retentiveness is gradually lost and the intellect becomes blunted. Aphasia, epileptiform seizures, and loss of control of the sphincters gradually develop, and death takes place in a state of emaciation and complete dementia.

Yet at autopsy little unusual may be noted on naked eye examination of the brain. In the few cases that have been adequately described the histological appearances have been so variable that it is impossible to give a comprehensive account of them. There has been reported, however, an alteration in many of the nerve cells amounting to fatty degeneration, chromatolysis, or even complete disappearance, with a reactive hyperplasia and fibrous metamorphosis of the glia. The most affected parts are the frontal and temporal cortex, the subi- 
culum and gyrus cinguli, while similar alterations may occur in the corpus striatum, the medial part of the optic thalamus, globus pallidus, substantia nigra, and cranial nerve nuclei. The parietal and occipital cortices appear to be largely spared. Some cases appear to have been predominantly cerebral rather than cerebrospinal.

There are three cases in the literature which Hallervorden (1930) has described as "atypical." The first was mentioned by von Economo and Schilder (1920), and it concerned a fifty-year-old-man who, following on a cold, developed pains and weakness in the legs. The illness lasted five years, and during the last five months of its course dysarthria, disorientation, dementia, and delirium supervened. The whole body became rigid and the face took on a Parkinson-like mask. Tendon reflexes were exaggerated and the plantar responses were extensor. Histologically, an increase of fat was found in the nerve cells of the cerebral cortex with some satellitosis but little cell atrophy. In the basal parts of the corpus striatum and substantia innominata there were symmetrically placed foci of glial overgrowth, together with a general proliferation of the glia. In the globus pallidus there was some cell atrophy, with reactive changes in the glia, and precipitates were found lying free, but there were no calcium deposits. In the cerebellum there was a fatty infiltration of the glial cells of the molecular layer and in the liver an interstitial hepatitis. This case is of considerable interest and it appears to be almost unique. In spite of the presence of hepatitis there is no resemblance either clinically or histologically to Wilson's disease. The second case was described by Fleischhacker (1924); the patient was a woman of forty, whose symptoms, in some respects, suggested paralysis agitans. There was a tremor of the upper limbs with transitory symptoms of a right-sided pyramidal lesion with spasm and paresis. Memory became impaired and she developed into a quarrelsome psychotic with ideas of persecution. The illness lasted twelve years. Histologically, there was found to be a diffuse nerve cell change of the whole brain, but especially in the large cells of the corpus striatum. The globus pallidus and substantia nigra were normal, but in the putamen there were extremely large glial cells with only a slight fibrillar metamorphosis. These cells were described by the author as being similar to Alzheimer's glial cells, only smaller. The third case was described by Gurewitsch (1921) ; it concerned a forty-three year-old man who developed severe mental alterations and neurological signs soon after an attack of pneumonia. At first the illness resembled Korsakov's syndrome, but the dementia later became profound and the cerebellar signs appear to have been considerable. At autopsy there were extensive degenerative changes in the nerve cells of moderate degree and an increase of cortical blia. There were some perivascular infiltrations in the cornu Ammonis, but these appear to have represented an isolated finding. There was hyperplasia of the glia in the corpus striatum and some degree of the same in the thalamus, red nucleus, and olives. The dentate nucleus was completely destroyed, but the cortex of the cerebellum and the cord were intact. A case not unlike this, but having some resemblance also to the group of parenchymatous cerebellar atrophies with mental changes, is to be reported elsewhere (McMenemey and 
Pollak). Marinesco and Draganesco's case (1929) of a child of six years with the syndrome of Fœrster appears to resemble the Creutzfeldt-Jakob syndrome in many respects.

The first of Davison's (1932) cases falling into the so-called "CreutzfeldtJakob" group of diseases showed atrophy of the small muscles of the hands with corresponding changes in the anterior horn cells. In addition there are a few examples in the literature of "amyotrophic lateral sclerosis with dementia." That these are instances of the same order of disease seems very likely.

Nikitin (1925) described another variant of this disease, the clinical type being predominantly cerebellar. The characteristic feature in this case was the striking involvement of the white matter of the cord; he called it " sclerosis cerebello-pyramido-intercorticalis."

Davison suggests "disseminated encephalomyelopathy" as a good descriptive title for this disease to cover its underlying pathology, but until more is known about it he is in favour of retaining the title given to it by Jakob of "spastic pseudosclerosis." Wilson (1940) has shown this latter term to be both inaccurate and unsuitable. It would seem best to retain the names of Creutzfeldt and Jakob until more is known about this condition, and seeing that its real entity is in doubt to regard it as a syndrome rather than a disease. It remains at present a convenient dumping-ground for several instances of atypical presenile psychosis of unknown origin which run a rapid course and have for their histology a parenchymatous degeneration of the brain with some glial hyperplasia. Heidenhain's (1928) cases have been included in this group, but the early onset of amaurosis in the first two was more in keeping clinically, though not histologically, with Schilder's disease. Hallervorden (1930) and Jansen and MonradKrohn (1938) have both considered the possibility, in view of isolated examples wherein the cerebral vessels have shown occasional perivascular lymphocytic cuffing, of epidemic encephalitis in an unusual form; the likelihood cannot be seriously entertained. A more important question is the possible relationship of this disease to pellagra, with which it has certain histological features in common. In a high proportion of cases of the deficiency disease, however, there is collateral evidence in the form of a history of gastrointestinal upset or of the findings of skin lesions. It is uncertain whether cerebral forms of the disease may occur in the absence of more widespread symptoms and signs, but if so they would fall into line with the cerebral form of the Creutzfeldt-Jakob syndrome. The similarity, however, is sufficiently close to suggest an obvious line in treatment for such cases of psychosis, whilst the occasional reporting of amyotrophy warrants the simultaneous exhibition of vitamin $\mathrm{E}$.

A familial incidence in this disease has so far been described only once: Meggendorfer and Stender (1930) report the case of a woman of forty-six whose brother, aged forty-four, was previously under the care of Kirschbaum (1924). With so few instances adequately described it would be illogical to be dogmatic as to the essential character of this syndrome, but one cannot but see a striking resemblance between it and Huntington's chorea, neither can one fail to see 
that this condition forms a bridge between Huntington's chorea and the parenchymatous atrophies of the cerebellum, several of which are now known to be familial.

\section{Primary Parenchymatous Cerebellar Atrophies}

This group includes a series of presenile and senile instances of degenerative processes in the brain, the brunt of which falls on the highly organized cells of the cerebellum, the pons and the olives; it would appear, however, that other neurones may be involved, amongst them those of the cerebral cortex. The interrelation of these diseases is still far from clear, but a classification was suggested by Marie, Foix, and Alajounine (1922) which served for a time. Wilson (1940) adopted an anatomical classification, which is perhaps more satisfactory. The origin of the disease is attributed by Parker and Kernohan (1933) to a premature senescence of the Puakinje cells.

Coincident involvement of the cerebral cortex in this group of diseases has been mentioned by Fickler (1911), Schrœder and Kirschbaum (1928), Bogært (1928), Mathieu and Bertrand (1929), Bogært and Bertrand (1929), Guillain and Bertrand (1929), Akelaitis (1928), and Richter (1940). Thus it would seem that the subnormal intelligence which characterizes most instances of Freidreich's ataxia can be paralleled in those cerebellar atrophies occurring later in life. Akelaitis (1938) described a family in which there occurred in three generations five cases of primary parenchymatous atrophy of the cerebellar cortex in association with mental deterioration. He groups the hereditary and familial forms of cerebellar atrophy into, (a) olivopontocerebellar (ascending or cerebellopetal), and (b) primary parenchymatous (descending or cerebellofugal). The presence of these familial forms of the parenchymatous cerebellar atrophies at once serves to emphasize their abiotrophic nature and to bring them more into line with those familial degenerations of the cerebellum met with in younger persons. Mathieu and Bertrand (1929) emphasize the difficulty of differentiating between hypogenesis and progressive degeneration.

Wilson (1940) explains the psychical symptoms of primary parenchymatous cerebellar atrophy as being due to their toxic accompaniment: such would be, in part, an explanation of Greenfield's (1934) cases, but it would not account for all. Moreover, the atrophy of the Purkinje cells could equally well be explained on the basis of a toxæmia, for their instability is notorious and is probably far greater than that of the cells of the cerebral cortex. It is difficult to get away from the view that both the cells of the cerebral and cerebellar cortex are, in this disease, unusually susceptible to external influences, owing to an inherent lack of vitality.

There are two interesting cases in the literature which appear to be related to this group. The first was described by Claude, Lhermitte, and Baruk (1932). The patient was a man of fifty-seven, who, two years after an injury to the skull, began somewhat suddenly an illness which eventually showed itself as a profound emaciation, associated, paradoxically enough, with boulimia. The neurological disturbances amounted to a right-sided hypertonia, aphasia, and pseudobulbar signs, while the mental picture was dominated by negativism, a 
lack of interest, disorientation, gesticulation, and turbulence, especially at night. Although the symptoms and signs would at first glance suggest an encephalitis, the histological findings showed no evidence of this: there was found an extensive nerve cell atrophy with secondary gliosis of the frontal cortex, lenticular and caudate nuclei, and the optic thalamus. The authors remark that only a formidable toxic agent could account for the lesions.

The other case was reported by Stern (1939) and it appears to be unique in the literature. The subject was a forty-year-old man who developed a severe dementia associated with iridoplegia, hypersomnia and forced grasping and sucking movements. The illness was of short duration. The histological analysis revealed a symmetrical degeneration of the nerve cells with consecutive gliosis of most of the optic thalamus and similar but less conspicuous changes in the cerebral cortex and inferior olives.

These diseases have all been included in the one group because they have this in common: they all reflect the importance of the constitutional factor in degenerative states of the central nervous system.

\section{Dementia as a Symptom of Intracranial Tumour}

Although a brain tumour seldom causes profound dementia, some degree of mental deterioration is not uncommon, and it may be the presenting, and for a time, the only symptom. In middle age the diagnosis of intracranial tumour may offer unusual difficulties: the early symptoms and signs may simulate those caused by cerebral arteriosclerosis or syphilis, and the occasional co-existence of a brain tumour with those conditions has to be borne in mind. Moreover, in a high percentage of cases, headache, vomiting and papillodema may be absent (Hastings, 1939). A reason that has been suggested for this is that in the middle-aged and elderly, the subarachnoid space is more capacious than in younger subjects and a tumour can expand to a considerable size at the expense of this space before compensation is disturbed and symptoms of increased intracranial pressure result.

That the difficulties of diagnosis are very real is stressed by Hastings (1939) who found that at the Philadelphia General Hospital between 1928 and 1935, out of a total of one hundred and seventeen cases of intracranial tumour, there were twenty-five instances over the age of forty in which the correct diagnosis was established only at autopsy.

\section{Is the Dementia a Primary or Secondary Symptom?}

Symonds (1931) referred to the diagnostic importance of the mental changes which come before the onset of symptoms of increased intracranial pressure. The early alterations may be regarded as primary symptoms attributable to the nature and situation of the tumour, just as there may be paralysis, aphasia or defects in the visual fields before the secondary symptoms of increased intracranial pressure become manifest. It is, therefore, of prime importance to obtain a careful history, not only from the patient, but from his relatives and associates. The first signs and symptoms may appear so trivial to the 
patient or his friends that their true importance is not realized. For this reason, the method of direct inquiry may have to be employed and attention directed specifically to any peculiarities of temperament or behaviour which may have been noticed, however slight or transient. To appreciate the full significance of these early symptoms, it is necessary to know as much as possible about the patient's " pre-psychotic personality" (Sachs, 1930).

Mental symptoms have been separated by Kinnier Wilson (1940) into two kinds, general and specific. The former, which can justly be described as negative rather than positive, amount to inattention, indifference, impaired memory and insight, and slowness of response. It is these symptoms of a general nature which are most commonly seen and they are more often due to the raised intracranial pressure than to the tumour itself. Alford (1937) goes so far as to stress the decisive value of these symptoms of a negative kind over more positive psychological findings in the study of the early intellectual defects of cerebral lesions. Intellectual disturbances are attributed by Kinnier Wilson (1931) to implication of the long association fibres, whereas emotional upset is usually found to be due to tumours near or within the ventricular system. According to Symonds (1931) mental deterioration is related to the total amount of white matter destroyed.

As a tumour grows, further symptoms appear and there may be signs of pressure upon important pathways in its vicinity. These symptoms may be due to involvement of the brain tissue by the tumour or to the general rise of intracranial pressure resulting from it, and they include dysarthria, apraxia, forced grasping movements, hemiparesis and epileptiform attacks. Papillœdema is said to be late if the tumour is situated anteriorly. The cerebrospinal fluid may show a rise in protein content, more especially if the neoplasm involves the basal surface of the brain (De Vet, 1936) or else has infiltrated to the cavity of a ventricle. Mental symptoms may be due not only to infiltration and destruction of brain parenchyma by the growth of local or general brain œdema, but may follow on a disturbance of the speech mechanism (Holmes, 1931) when the unhappy patient finds himself losing touch with his fellow men. They may also occur after impairment of cortical function other than that of speech control.

\section{Dementia as a Guide in the Location of a Cerebral Tumour}

When dementia is the presenting symptom, one's attention is naturally directed to the frontal region of the brain. But tumours situated in other localities may cause dementia, whilst it is within the experience of many that frontal neoplasms may occur without any disturbance of the intellect or emotions. The whole subject of mental symptoms associated with cerebral tumours was reviewed in a discussion at the Royal Society of Medicine in 1931. The general conclusion at that time was that the localizing value of mental symptoms was practically nil. Nevertheless, it is expedient to review the subject in the light of certain studies which have been recorded since that date.

Frontal.-Occasionally it happens that considerable portions of the frontal 
lobes can be implicated with astonishingly slight disability. Such a case was described by Ackerly (1935). The patient was a woman whose right frontal lobe was removed on account of a midline meningioma which had caused severe compression also of the left frontal lobe. Two years afterwards there was said to be no significant diminution in intelligence or disturbance of emotion or general behaviour: the only symptom was a certain lack of distractibility. Rowe's (1937) patient, whose right cerebral hemisphere was removed on account of an astrocytoma, had as residual signs only a slight loss of inhibitions, some impairment of memory and a slightly disordered emotional tone. Dandy (1928) described five instances of removal of a whole hemisphere: in the three cases in which postoperative examinations were full there were found to be practically no mental symptoms. Brickner (1932), however, describes considerable alteration in personality and a loss of intellectual power after removal of both frontal lobes, and Rowe (1937) concludes that the higher cerebral functions of man are more severely altered by bilateral frontal lobe lesions than by corresponding or even more extensive lesions of any other area, an opinion which would appear to be substantiated by the findings of others. Thus Frazier (1936), in a review of 105 cases of frontal lobe tumour, draws attention to the importance of a bilateral involvement of the brain for the development of mental symptoms. Moreover, Duus (1939) has analysed the psychic disturbances accompanying tumours of the orbital part of the frontal lobe and from a study of five cases of his own and twenty-five in the literature he concludes that they are usually due to bilateral meningiomas occurring in middle-aged persons. He noted that character changes developed consistently early, whilst the more general signs of raised intracranial pressure came later. Schrœder (1939), however, after presenting eighteen new cases of frontal lobe tumours observed that the symptoms depended more on the accompanying œdema than on the actual involvement of the brain. Mental symptoms are usual, he says, because the white matter is so often involved in the œdema, which serves to obstruct the blood flow, thus impairing nutrition and function.

Thus it would appear from these various observations that it is the bilaterality of frontal cortex involvement which is of prime importance for the development of mental symptoms. Worster-Drought (1931) states that a left frontal lobe lesion, in his experience, is more liable to give rise to disorder of conduct and even dementia than a lesion of the right frontal lobe, the latter being more likely to be associated with amnesia and confusion.

The more recent psychological studies in frontal lobe lesions such as those of Goldstein and Katz (1937) have shown that a great deal is to be learnt by a careful analysis of the mental symptoms, adding that "it appears justifiable to make a diagnosis of a lesion of the frontal lobes on the basis of mental changes." The studies of Penfield and Evans (1935), too, show the importance which must be attached to a thorough knowledge of the patient before symptoms of a negative character can be fully evaluated.

Temporal.-Golla (1931), in a series of fifty-five cases of intracranial tumour causing mental symptoms collected from the Claybury and Maudsley hospitals, 
found that nineteen of them were situated in the temporal whereas only eleven were in the frontal lobe: the majority of them were in the right temporal region. Collier (1929) remarked that the most dramatic mental changes that he had seen attributable to a brain tumour had been in instances of neoplasms in the temporal lobe, the outer surface of the occipital cortex and the splenium of the corpus callosum respectively.

Corpus callosum.--Involvement of the corpus callosum by neoplasms may give rise to mental disturbance, but some degree of apraxia and hemiparesis is usually present to give a clue to the locality of the lesion. Ironside and Guttmacher (1929) remark on the similarity of the symptomatology to that of cerebral arteriosclerosis, especially when psychical changes co-exist with bilateral pyramidal signs and tremor or other involuntary movements. It is interesting to note that the apparent ataxia which characterizes some of these cases is attributed by Barre (1939) to an impairment of attention. Craner (1936) described six cases of tumour involving the corpus callosum. It would appear from his observations that growths involving the splenium may cause symptoms of progressive loss of memory for recent events, an appearance of mental confusion, disorientation and unsteadiness of gait. In the two examples in which only the splenium of the corpus callosum was involved headaches were absent and papillœdema was questionable in one (case 6) and had subsided in the other (case 5). In the latter case symptoms had been present for eight years. Although it would be rash to attribute too much importance to so small a series it is worthy of note that those two cases which presented themselves as early instances of dementia tended to lack the classical triad of brain tumour symptoms.

Third ventricle.-Riddoch (1936) reported two instances of tumours of the third ventricle, one of them a colloid cyst, giving rise to dementia in the absence of headache and changes in the fundus oculi. Nielson and Raney (1940) stress the importance of alteration in effect and personality, and also amnesia for recent events, in establishing the presence of tumours in the region of the third ventricle.

Basal ganglia.--Smyth and Stern (1938) have commented upon dementia as a finding in certain cases of tumour involving the optic thalamus. In four out of six instances mental symptoms occurred early and in two of them dementia was the most outstanding sign: in these two cases there was bilateral involvement of the medial thalamic nuclei and the authors make a tentative suggestion that this may be an important factor in determining the appearance of dementia.

Posterior fossa.-Brain (1931) commented on the profound mental disturbances which may be associated with tumours of the posterior fossa.

Mental hospital cases.-Cerebral tumours rarely present mental symptoms sufficient to justify admission to a mental hospital. Figures were quoted by Golla in 1931. An analysis of material collected from 1,320 consecutive autopsies performed at Napsbury Hospital showed only twenty instances of intracranial tumour representing 0.41 per cent. of admissions: in only nine of these $(0.205$ per cent.) were the symptoms responsible for their admission to 
hospital. The presenting symptom, too, was nearly always mental confusion which tended to obscure any dementia which may have developed. Perhaps metastatic neoplasms are the commonest tumours to cause mental confusion, and foremost amongst them must be listed the bronchial carcinoma. Occasionally, a growth may spread diffusely over the meninges: an example wherein a woman of fifty-eight had symptoms of ingravescent dementia for five months prior to the onset of more general symptoms of raised intracranial pressure was referred to by Greenfield (1938), who aptly points out how readily such a condition of the meninges may be overlooked at autopsy.

\section{Conclusion}

Out of all that has been written about mental symptoms in intracranial tumours, the one fact which emerges clearly is that we have yet much to learn about them. The localizing value of these symptoms is of great psychophysiological interest, but for purposes of diagnosis more exact methods, such as ventriculography, have to be employed.

\section{Aneurysm and Trauma as Causes of Dementia}

Intracranial aneurysm.-As the possibility of an intracranial aneurysm must be entertained in the differential diagnosis of a cerebral tumour, brief mention will be made of it here. If an aneurysm arises from the anterior communicating or from one of the anterior cerebral arteries and attains any degree of size, it may cause considerable distortion of the frontal lobes and interfere with their nutrition with consequent development of mental symptoms. But dementia, without localizing signs, is unusual and headache is a very frequent symptom. Moreover, a history of one or more acute phases of the illness corresponding to periods of rapid distention of the aneurysmal sac can often be elicited. It should be emphasized again that by no means all patients with frontal lobe lesions, be they tumour or aneurysms, develop mental symptoms ; there would appear to be some inherent and predisposing factor which determines this. Kinnier Wilson (1940) has said that the mental symptoms may spring from the soil as a purely indirect sequel of the growth. Aneurysms are found at autopsy at all ages, but they seldom give rise to symptoms before the age of twenty. Not a few of them are symptomless until the advent of middle age when the vascular system becomes less elastic and when the blood pressure may begin to rise.

Trauma.-A few cases of progressive dementia are accounted for, either by a chronic subdural hæmatoma, or, less frequently, by cerebral concussion giving rise to subsequent diffuse glial scars. The former occurs most commonly over the parietal region and one-third of the cases are bilateral. The symptoms and signs may resemble closely those of a cerebral tumour so that it becomes of prime importance to inquire not only for a history of trauma but for accurate particulars of the mental state of the patient immediately following the accident. In this connection one recalls the frequency with which persons 
with cerebral tumours recollect blows on the head which they are quick to associate with their symptoms; although there is some evidence to show that there is an association between them, more often than not the occurrence is fortuitous. But the blow is seldom as severe as is usually encountered in instances of subdural hæmatoma. Nevertheless, these latter patients occasionally find their way into mental hpspitals without any clear history of trauma, whilst alcoholics frequently subject themselves to trauma but often fail to recollect any such event. A history of alcoholism and the possibility of other toxic agents will be reviewed during the anamnesis, but such diseases, as well as syphilis and other disorders which are general and are not just confined to the brain, will be readily recognized in a general examination of the patient because of the collateral manifestations.

The so-called "post-concussional syndrome" gives a history of severe headaches made worse on moving the head. The more striking symptoms are attacks of giddiness with vomiting, but of greater interest are the neurasthenic tendencies which develop later with irritability and sometimes more distressing alterations of personality. Ultimately symptoms of dementia may ensue with gradual deterioration of memory and intellect, slovenliness and melancholia. This interesting disorder has for its histological basis a neuronal degeneration of the cerebral cortex attributable in part to the sudden vascular alterations caused at the time of the injury. It is not often that the dementia is severe and usually the patient is only too ready to relate the circumstances of the injury.

\section{Syphilis as a Cause of Dementia}

It is unnecessary to refer to so well recognized a cause of dementia as general paralysis except to stress the fact that the blood Wassermann reaction may, in cases wherein syphilis was contracted many years previously, be reported sometimes as negative even in the absence of a history of antisyphilitic treatment. This impression is confirmed by Petersen (1937) who found a negative Wassermann reaction in the blood in as high a proportion as 11.6 per cent. of cases. This is contrary to what is stated in many of the textbooks which maintain that the blood Wassermann is positive in 100 per cent. of instances. The employment, however, of a sensitive Wassermann technique when congenital, oldstanding or treated lues is expected will usually detect all general paretics, but the Wassermann tests in general use, which are designed rather to assist in the recognition of cases requiring antisyphilitic treatment, may miss these weak positive reactors. Thus it is not unusual to find patients admitted to hospital with the story of having had a negative blood test outside, yet subsequent examination has shown their blood to be weakly positive with a sensitive technique. In the laboratory diagnosis of neurosyphilis it is desirable to make use of one or more of the flocculation tests as auxiliaries. The Meinicke and Müller reactions, for instance, have proved themselves invaluable for the recognition of oldstanding and treated cases. But, if an examination of the blood proves unhelpful, the cerebrospinal fluid will nearly always reveal the true state of affairs, authentic instances of untreated general paralysis not 
showing changes being distinctly rare. Here again the employment of a flocculation test is helpful: in particular the Müller reaction would seem to offer valuable confirmation of old-established disease. It is a wise practice always to collect both blood and fluid at the same time from any case in which general paresis has to be excluded. This provides against the possibility of this disease being missed simply because the blood Wassermann happens to be negative. This is of particular importance in mental hospital practice where many of the patients may have received sufficient antisyphilitic treatment to render the blood Wassermann negative before the advent of mental symptoms. The importance of a thorough serological investigation must be stressed because not a few instances of naturally or therapeutically arrested general paresis have, in the past, been described as examples of idiopathic presenile dementia, the clinical and histological features being atypical of the former. General paresis should be diagnosed at the stage when mental symptoms are appearing and before the advent of physical signs in the central nervous system. "Stationary" paralysis may give rise to difficulty in diagnosis, for the smouldering nature of the disease may be reflected in indefinite serological findings. Galbraith (1940), however, has reported a case, having diagnostic serological confirmation, which was stationary for thirty-one years, only one year less than the classical example described by Gaupp and Alzheimer (1907). Examination of the blood and cerebrospinal fluid plays therefore an essential part in establishing the diagnosis, and it is in order to avoid missing this disease in its early, and especially its atypical, forms that one must employ them as a routine examination in any case of dementia.

Short of general paralysis dementia may occur in other varieties of neurosyphilis and particular mention should be made of syphilis of the cerebral blood vessels. If this disease is allowed to establish itself one or more thromboses may occur as the result of an obliterative endarteritis with infarction of the brain of greater or less degree depending upon the size and location of the obstructed vessel. When the thrombotic areas are found scattered throughout the white matter of the cerebral hemispheres, as sometimes happens, and particularly when the softened areas are placed anteriorly, it is little wonder that dementia ensues. Histological examination of such a brain reveals a well ordered reparative activity on the part of the mesoglia and a relative lack of any degree of active syphilitic inflammation. For these reasons, if the disease is taken early, the prognosis is hopeful and the patient may obtain many years of useful life.

\section{Arteriosclerosis and Dementia}

Under the heading of " arteriosclerlosis" there is a bewildering variety of conditions which have their origin in an impoverishment of the blood supply to the brain due to disease of the blood vessels. Arteriosclerosis is not a disease (Allbutt, 1915) but a pathological process. Evans (1923) has likened the term " arteriosclerosis" to a crêche for children who have not known their 
parents or who have so little individuality that they cannot be distinguished apart.

It is not proposed to do more than outline the varieties of cerebral arteriosclerosis, but reference will be made first to certain difficulties met with in the recognition of this disease.

In the first place, arterial disease may be strictly local in its incidence in the body, so that it is difficult to deny the possibility of cerebral arteriosclerosis in a person who has passed the fortieth year, even if the cardiovascular system, as a whole, is above reproach. Neuberger (quoted by Biggart, 1936), studying this dissociation, found arteriosclerosis of the peripheral vessels in only 10 per cent. of cases of cerebral vascular disease. Even the retinal arteries may be spared when the intracranial vessels are actively involved: and the converse is true, for one cannot be certain that the cerebral vessels are diseased even if the retinal or radial arteries are tortuous. This patchy distribution of arteriosclerosis often gives rise to faulty diagnosis. On the other hand, the relationship between changes in the vessels of the brain and kidneys is more intimate than that which obtains between the cerebral and peripheral vessels: in old age they often appear to react almost identically so that there would seem to be a common cause for their behaviour. It has been said that the reason for the erratic incidence of arterial disease lies in the factor of local strain. But this explanation should not close one's eyes to other possibilities, such, for instance, as the likelihood of sepsis in the near locality contributing to the disease. In this connection it has been suggested that chronic ethmoidal and sphenoidal sinusitis may play some part in the ætiology of sclerosis of the vessels constituting the circle of Willis, but the evidence has not been convincing. The important fact, however, which emerges from collected experience is that cerebral arteriosclerosis may be unaccompanied by general arteriosclerosis. But not only may arterial disease be localized to the brain, it may be confined to one part of the brain: perhaps the most striking instance of this is that variety of arteriosclerosis described first by Binswanger (1895), and more recently by Farnell and Globus (1932), affecting the subcortical arterioles and giving rise to a symptomatology and histological picture which bears some resemblance to Schilder's disease.

Secondly, we are, at present, not skilled in recognizing the earliest stages of arterial disease. It requires a microscope to recognize thickening and proliferation of a capillary vessel, but preceding the structural changes in the capillaries there must be alterations in function which we are unable to detect, for we have no means, as yet, of examining in a critical way the capillary bed of the brain during life. The importance of functional vascular disturbances cannot be overrated, for this conception has dominated recent work on cerebral arteriosclerosis and hæmorrhage (Stern, 1938). One concludes, therefore, that it is almost impossible to say whether cerebralvascular changes have begun in any given case or not. Moreover, even a vessel with advanced disease may still be able to function without apparent detriment to the parenchyma which it subserves.

Lastly, one must reckon with the fact that senescence is entitled to a certain 
amount of vascular change and it is sometimes difficult to decide if this allowance has been exceeded. These changes have been described by Baker (1937). Senescence is not to be regarded as a disease: neither must the involutional processes accompanying it be regarded as pathological events, but senescence occurring before its time is abnormal. And here perhaps is some justification for retaining the terms " presenium " and "senium " in our nomenclature: for after the age of sixty, we expect to find some vascular alteration, but before this age we are justified in regarding such changes as pathological.

The occurrence of arterial changes secondary to already existing disease requires only to be mentioned because of the possibility of its being mistaken for primary vascular disease. There are many examples of this in neuropathology, particularly in the degenerative disorders, where we find vessels removing products of catabolism and becoming themselves diseased as a result of the local stasis and accumulation of lipoids.

Finally, a not infrequent histological anomaly is the presence of a much diseased vessel and an apparently healthy area of irrigation; or one may find pathological reactions around perfectly healthy looking vessels. When faced with these problems one must recall the anastomotic pattern of the cerebral vessels and the fact that not all transudates from vessels can be expected to show themselves in histological preparations.

The histological variants of cerebral arteriosclerosis short of encephalomalacia are catalogued by Hassin (1933) as follows: (1) Alzheimer's senile cortical sclerosis ; (2) perivascular gliosis; (3) Binswanger's " chronic subcortical encephalitis "; (4) Pierre Marie's état lacunaire, and Grasset's progressive lacunar cerebrosclerosis; (5) état criblé (Durand-Fardel); (6) état vermoulu (pierre Marie); (7) verrucose atrophy (Spatz); and (8) schizogyria (Mittlebach and Spatz). Some of these conditions, however, are only to be expected in the senile decades. Greenfield's classification (1938) of the forms of presenile dementia associated with vascular disease is simple and adequate. In his first category, the one most frequently met with, he places all examples with softenings or hæmorrhage, adding that little is to be gained by giving different names to forms in which the predominant change is of one or other character. He mentions, however, a rare variant met with in subjects of hyperpiesis in which multiple slit-like hæmorrhages are found chiefly in the subcortical white matter. He suggests that the pathogenesis of this form of the disease, as well as Binswanger's encephalopathy, may be related to the relative absence of anastomoses in the long vascular branches going to this part of the white matter. For his second type he recognizes the verrucose or granular atrophy of the cortex which is usually found in association with renal arteriosclerosis and hyperpiesis. This condition, which affects in an irregular manner both the nerve cells and fibres in the cortex and is associated with an overgrowth of neuroglial fibres, depends upon sclerosis of the small cortical arterioles and is presumably identical with the disease known as diffuse hyperplastic sclerosis (Evans, 1921) and arteriocapillary fibrosis (Gull and Sutton, 1872). These latter authors described the changes in the pia mater, whilst Evans paid special attention to the arterioles of the medulla and midbrain. 
The third form of progressive vascular disease, often associated in life with hypertension, is that in which no naked-eye changes are present either in the vessels or in the texture of the brain apart from indefinite thinning of the gyri. There is proliferation of the intima in the small cortical vessels together with numerous and widely scattered areas of focal degeneration or rarefaction (" lichtung") of the nerve cells. The glial alterations are minimal. Greenfield regards this form of cortical disease as closely allied to the changes described in Kræpelin's presenile psychosis, and also to those found in epileptics associated with mental deterioration.

Cerebral arteriopathy, in one of its many forms, contributes a fair proportion of the cases of dementia in the presenile group. Hypertension may be absent (Grünthal, 1935). In general, the progressive mental deterioration is associated with focal signs which have their origin in the disseminated lesions which we have referred to. The two most helpful points in the clinical recognition of the disease would appear to be the retention of insight until late on in the illness and the frequent occurrence of fluctuations and remissions in the course of the disease. Neurological signs are common, especially if one or more of the vessels has become occluded. Mental changes with apraxia are said to develop in the absence of any paralysis, however, if the callosal branches of the anterior cerebral arteries are occluded alone. An increase in the protein content of the cerebrospinal fluid may occur, especially if there is some complication such as cerebral thrombosis, uræmia or congestive heart failure. However, this increase of protein seems less likely in cerebral arteriosclerosis than in intracranial tumour. In Merritt and Fremont-Smith's studies (1937) only 25 per cent. of the former had a protein content over 45 mgms. per cent. whereas the corresponding percentage for cerebral tumour was 69 .

\section{Miscellaneous Conditions which may cause Presenile Dementia}

There remain several diseases which may give rise to a picture of presenile dementia.

Schilder's disease.-Although at first thought to be essentially a disease of childhood, it is now known that it may be met with later in life. In Bouman's series of one hundred cases of diffuse sclerosis, eleven were over the age of forty.

The essence of the pathology is a gradual dissolution of the periaxial white matter with a resulting gliosis. Sometimes familial, many different histological varieties of it are seen suggesting all stages between a frankly infective and a mildly degenerative process. No doubt it has more than one cause and the ætiological factors, which, as MacNamara and Dickson (1932) and Meyer and Pilkington (1936) have suggested, may be extracerebral, may differ in two cases which histologically are identical. Bogært and Dewulf (1939) have described an example of seventeen years' duration following on a fall. Meyer and Tennent (1936) suggest the possibility of avitaminosis as a cause. Globus (1932) comments on the frequency of a gastrointestinal onset, while Winkleman and Moore (1939) describe a case with sudden onset at the 
age of thirty-seven ushered in by an infection of the upper respiratory tract. These last authors speak of the need for a search for " a common denominator." The classical type of Schilder described in children frequently had a symmetrical spread of the lesion from the occipital poles anteriorly. Amaurosis of central origin was therefore to be expected. But in older subjects this need not necessarily be the case and the first symptom may be referable to the frontal lobes (Ferraro, 1937). Undoubtedly, Schilder's disease to date has included other conditions which, in the course of time will be separated off from the parent group, but as we know it at present it is not always symmetrical in its progress, neither is it invariably progressive, certain examples of apparent arrest being known. It has been said that Schilder's disease must be reckoned with in the differential diagnosis of any case presenting evidence of a progressively destructive lesion of the brain, so that it must be considered as a possible, although a rare cause, of presenile dementia. With regard to nomenclature it would seem desirable to retain the term Schilder's disease for this group of maladies for the time being. "Diffuse sclerosis" is a less desirable title because it stresses that histological feature which is surely of secondary occurrence and importance. "Encephalitis periaxialis diffusa" is a convenient pathological name provided one is prepared to regard the inflammatory process in its broader sense as suggested by Aschoff to include reparative and regenerative phenomena as well as the frankly infective.

Marchiafava-Bignami disease.-Dementia is a symptom of this remarkable disease, the essence of which is a demyelination of the corpus callosum. Other parts of the white matter may be affected as, for instance, the anterior commissure, the brachium pontis, the subcortical white matter or even the optic chiasma. According to King and Meehan (1936), the process is related in some way as yet unknown to the vascular system. The first three cases were described together as a clinical entity by Marchiafava and Bignami in 1903. Since then some forty examples have been described, but they have all been Italian men. The first case to be reported from America (King and Meehan) was an Italian. It is possible now that the disease is becoming better known that more cases will be recognized and that it will be found not to be confined to the Italian race: on the other hand, we may have, in this disease, a true example of a racial constitutional weakness manifesting itself when precipitating external influences are brought to bear on it. An alcoholic history or a family history seems to be usual. King and Meehan summarize the clinical findings as follows: emotional disorders, exaggerated excitability and irrascibility or else apathy, moral perversions and sexual misdemeanours leading to intellectual decay and dementia sometimes with confusion. Fits may occur and tremors, dysarthria, transitory hemiparesis and paraparesis are common. There is much wasting in the late stages of the illness, the duration of which is given as from three to six years with a tendency to remissions.

"Toxic encephalopathies."-Mental deterioration, sometimes of considerable degree, may be associated with certain known toxic factors. Whether these toxic agents, and they include alcohol, lead and uræmia, are primarily the cause of the dementia or whether they are precipitating factors in constitu- 
tions mentally unstable is not known. The latter alternative would seem to be the more likely, but it has been suggested that other factors, such as secondary avitaminosis consequent upon chronic atrophic gastritis may play some part.

An atrophy of the brain attributable to alcoholism in a presenile person is unusual, but some degree of cell change is common; its amount, however, seems to bear little relationship to the clinical symptoms. Morel (1939) has described a degeneration of the third layer of the frontal cortex in alcoholic psychotics.

The diagnosis of these cases is usually aided by the findings of some signs of peripheral neuritis. Alcoholism sometimes presents itself in the form of a pseudoparesis with dementia ; but alcoholism and general paresis may and do frequently coexist, and this fact has been advanced as the probable reason for the better prognosis in cases of general paresis of the exalted type as compared with those of the melancholic variety, for the former tend to show a greater addiction to alcohol, so that with institutional treatment a greater amelioration in their symptoms is to be expected.

Other diseases may cause regression of the mind in middle-aged persons, but they have been excluded from this study because the dementia, when present, occurs late on, and is not the most prominent symptom. For this reason epilepsy, disseminated sclerosis and epidemic encephalitis have been omitted. Marchand, Demay, and Naudascher (1938) have described the case of a woman of fifty-seven who developed an agitated melancholia. Death occurred two years later after a short attack of bronchopneumonia. At autopsy they found a tuberculous meningitis and two tuberculomas which were thought to have contributed towards the state of presenile dementia.

There remain two diseases-presbyophrenia and "simple" presenile dementia-which have been hinted at by several observers but about the pathology of which there is still doubt. Whether they are the same entity or both stages in the development of Alzheimer's disease or even cerebral arteriopathy remains to be seen. The terms would appear to be convenient in a clinical classification, but at present their pathological individuality is uncertain. Fischer (1910) recognized a presbyophrenic dementia as distinct from Alzheimer's disease on pathological grounds, but Henderson and Maclachlan (1930) regard them as different stages in the same process. A true decortication would seem to occur also in some instances which clinically fall into the groups of involutional melancholia and the late form of schizophrenia, but there is the possibility that they may be mixed cases. There would, however, seem to be some theoretical reason for recognizing a " simple " presenile dementia wherein the atrophy, unlike Pick's disease, would be generalized and not confined to one or more parts of the brain. Such a condition would serve as a link between Pick's disease and the Creutzfeld-Jakob syndrome.

\section{The Rôle of Abiotrophy}

The term " abiotrophy" was first employed in 1902 by Sir William Gowers at a lecture delivered at the National Hospital. Choosing for his text the 
familiar example of baldness, he propounded the theory of limited vitality of organs and referred to certain nervous disorders wherein a particular system manifested a weakness throughout a family. This conception of abiotrophic diseases had been mentioned three years previously at a meeting of the Pathological Society of London when he replied to an address delivered by Dr. F. W. Mott on the pathology of tabes dorsalis and general paralysis. Dr. Mott had asked whether the toxic agent did not lower the durability of the nerve elements so that some other factor induced a premature decay. Sir William Gowers replied that he "had long felt that this disposition to decay, sometimes inherent, strongly or slightly, seemed to be induced artificially by toxic and perhaps other influences." In his Croonian lectures for 1900, Mott referred to the inherent vitality of the neurone as being the determining internal cause of disease of the central nervous system. The conception, however, was not new. Thus Powell, in Quain's “Dictionary of Medicine," 1883, referred to a group of diathetic diseases which "are of the nature of premature senility, attacking certain tissues or organs . . . from some inherent defect in their vitality," whilst in 1855 , Walshe talked of "diseases apparently generated and sustained by an intrinsic blood poison resulting from some perversion of the nutritive processes of the individual." In 1830, we find Forbes Winslow quoting Gooch as having said that many of the diseases commonly attributed to cerebral congestion arise from a deficiency of nervous power and require for their removal " not depletion but support." Going back farther, we find the importance of the intrinsic factor in disease stressed by many writers: thus Cheyne (1725) remarks " the Failure may be in the Patient himself" and again "some chronical Distempers are such . . . by being Hereditary and interwoven with the Principles of Life, as never to be totally overcome," whilst Cooke (1685) says that " the Causes of diseases may be remote, between which and the Disease comes another Cause which is not in all diseases: this latter is either internal (called the Antecedent) consisting in the humours which have their being in the Body, which though at present they act not yet they may generate a disease." Finally, Aristotle had talked of "a lack of the inborn capacity of easy resistance to unhealthy influences" (Garrod 1927).

The term "abiotrophy" has served as a useful cloak for ignorance, and, for this reason, has, at one time or another, come in for a certain amount of disfavour : nevertheless, every year brings to light additional instances of familial disorders of the central nervous system, each of which serves to strengthen the argument for the recognition of abiotrophy. The majority of the diseases referred to above have familial instances, i.e. Pick's disease, Alzheimer's disease, Huntington's chorea, Schilder's disease, the Creutzfeldt-Jakob syndrome, the cerebellar atrophies and even cerebral arteriosclerosis, whilst the remarkable racial incidence of the Marchiafava-Bignami disease is suggestive of the same constitutional trend. Abiotrophy, however, does not preclude further analysis and it should not be regarded as a teleological entity; for this reason, one must not despair of attempting treatment. According to Myerson (1939), constitution is profoundly influenced by environmental agents and many conditions which we at present rightly regard as hereditary had better 
be classed as constitutional. Myerson says " we may be chary of ascribing to heredity, dysfunction or lowered capacity when environmental circumstances are such as to favour the appearance of abnormality and inferiority and are unfavourable to full development. It is probable that we must look more to the earliest and earlier environments of man for the explanation of defect and aberration than to the later environmental situations, although they, too, have their place in the sun as explanatory of malfunction." An abiotrophic disease may, therefore, be conditioned by the lack of, or unavailability of, some ferment, vitamin or hormone which might conceivably be supplied therapeutically. In the realm of nosology, there are often the two factors, the endogenous and the exogenous : the former may be described as the abiotrophic tendency and the stronger this propensity is, the less will the exogenous factor need to be to precipitate the illness. Garrod (1927) says " in the abiotrophies the tissue defects are the most potent causative factors and the influence of external exciting causes is minimal." Rosenbach suggested that the vitality of the concerned tissues might be so low that even normal function overtries it. This view is paralleled by that of Critchley (1939), who refers to the possibility of involutional changes being localized to certain neuronic systems and appearing therein at an exceptionally early age. The exogenous factor, therefore, is often thought to be minimal and may be of the nature of a "subinfection" (Adami, 1914). Meyer and Cook (1937), however, note the frequency of pathological processes accompanying developmental lesions and they believe the extrinsic factor to be often of import. They say "more often than is realized, developmental arrest is only the indicator of the time of the damage and not the expression of an intrinsic, abiotrophic or faulty tendency of the tissue." The so-called extrinsic factor referred to by these authors, however, may, in point of fact, be intrinsic, for the gliosis which they regard as an index of bodily response to the extrinsic agent may have been determined by a biochemical aberration which can be regarded as an intrinsic dysfunction, although, it in turn, might be instigated by either an intrinsic or an external predisposing factor.

The concept of abiotrophy or tissue defect, therefore, is seen to imply more than an hereditary disposition, for it presupposes the constitutional factor which is dependent upon environmental influences. The importance of external agencies may, at times, be questionable, but it can be said in general, that it varies inversely with the inherent weakness of the tissue concerned.

\section{The Limitations of Histology}

The first classification of disease was, of necessity, based entirely upon clinical findings. In the nineteenth century, however, histology came to the aid of medical philosophy and a more accurate ordering of disease was possible. Yet in 1848 we find Graves warning us against " the fine-drawn and ill-founded observations of those who profess to account for every nervous disturbance during life by cerebral lesions." But morbid histology still furnishes the most 
useful means of classification although it cannot be regarded as ideal. It has many drawbacks. Savage (1899) said, on this very topic, "the debris in a wrecked house is the same whether the fire originated in lightning or a paraffin lamp." Histology reveals but a sight of the battlefield when the engagement is over, but even here some idea of the varying fortunes of the fight can be gained by a critical analysis of the evidence before one's eyes. The senile plaques are not in themselves a cause of dementia, but they are the outward and visible signs of the struggle between the host and the pathogenic agent which induced the symptoms of dementia. The same applies to the neurofibrils when they have adopted the bizarre cadaveric positions so characteristic of Alzheimer's disease. Moreover, there is no quantitative relationship between clinical and pathological changes in this disease and in senile dementia (Rothschild 1937). But in the realm of neuropsychiatry there are many functional and probably also biochemical abnormalities which cannot be made to reveal their presence by means of the fixatives and impregnations at our disposal. Pursuing the above analogy one might say that there may be little evidence on the ground of the serious aerial combat which has taken place some hours before overhead. As our techniques become more perfect, further histological revelations throw additional light on our knowledge of disease. The methods of impregnation with silver and gold and the benzidine-nitroprusside technique of Pickworth (1934) constituted distinct advances in the histological approach, and now we watch with interest the more recent attempts at histochemical analysis.

At present, the need is for a more critical study of those diseases of the brain which one might describe as histologically non-spectacular. They constitute the majority of the diseases of the mind. Histology, in this particular field, has, in the past, been disappointing, but more might be learnt from it then has been the case to date. Yet histology alone will not contribute all; the diseases must be studied from every possible approach.

\section{Conclusion}

It is to be hoped that researchers will devote more time to an exhaustive study of the interesting group of dementias met with in middle age. The histologist should receive every encouragement to examine material from such cases and good clinical data should be amassed for the benefit of subsequent workers in this field. More instances of familial diseases might be disclosed if more exhaustive family and environmental histories were taken : for the smaller the family the less chance is there of a familial disease manifesting itself as such. At present there is much confusion in this group of diseases, for the number of atypical cases which do not readily fit into any group is considerable. Nevertheless, the unitarians are in the ascendancy. We find von Braunmühl (1932) advocating that Pick's disease, Alzheimer's disease, and senile dementia, and perhaps other degenerative diseases as well, are varying 
aspects of the same general type of tissue reaction to disease. Jonesco-Sisesti and Strœsco (1939) argue on similar lines.

Having their origin at a time of life when physical and mental stress are often at their highest and when involutional processes are beginning, the presenile dementias may hold many secrets concerning the ætiology of organic disease of the nervous system, and they may be instrumental in clarifying our views on the much-debated problems of diathesis and abiotrophy.

\section{REFERENCES}

Ackerly, S. (1935). Amer. J. Psychiat., 92, 717.

Adami, J. G., and McCrae, J. (1914). Textbook of Pathology, 2nd Ed., 144.

Akelaitis, A. J. (1938). Amer. J. Psychiat., 94, 1115.

Alexander, L., and Looney, J. M. (1938). Arch. Neurol. Psychiat., Chicago, 40, 1075.

Alford, L. B. (1937). Amer. J. Psychiat., 94, 615.

Allbutt, T. C. (1915). Diseases of the Arteries including Angina Pectoris. Macmillan, London. Alzheimer, A. (1907). Zbl. Nervenheilk., 18, 177. (1911). Z. ges. Neurol. Psychiat., 3, 566.

Baker, A. B. (1937). Amer. J. Path., 13, 453.

Barre, J. A., Kabaker, Pernot and Ledoux (1939). Rev. Neurol., 71, 389.

Barrett, A. M. (1913). J. nerv. ment. Dis., 40, 361.

Benedek, L., and Lehoczky, T. (1939). Brain, 62, 104.

Biggart, J. H. (1936). Pathology of the Nervous System. E. and S. Livingstone, Edinburgh. Binswanger (1895). Z. Psychiat. von Laehr., 51, 804.

Bogaert, L. van (1928), quoted by Akelaitis, A. J. (see above).

Bogaert, L van, and Bertrand, I. (1929). Rev. Neurol., 1, 165.

Bogaert, L. van, and Dewulf, A. (1939). Arch. Neurol. Psychiat., Chicago, $42,1083$.

Bouman, L. (1934). Diffuse Sclerosis. Wright, Bristol. (1934). Brain, 57, 128.

Bouton, S. M. (1940). J. nerv. ment. Dis., 91, 9.

Boyd, D. A. (1936). Amer. J. Psychiat., 93, 155.

Brain, R. (1930). Proc. roy. Soc. Med., 24 (2), 1002.

Braunmühl, A von. (1932). Z. ges. Neurol. Psychiat., 142, 1.

Braunmühl, A. von, and Leonhard, K. (1934). Ibid., 150, 209.

Brickner, R. M. (1932). Proc. Ass. Res. nerv. ment. Dis., 13, 259.

Cheyne, G. (1725). An Essay of Health and Long Life, London, p. 174.

Claude, H., and Cuel, J. (1939). Ann. Méd. lég., 19, 173.

Claude, H., and Lhermitte, J. (1910). Encéphale, 5, 177.

Claude, H., Lhermitte, J., and Baruk, H. (1932). Ibid., 27, 177.

Collier, J. S. (1929). Brit. med. J., 2, 289.

Cooke, J. (1685). Mellificium Chirurgiae, London, p. 360.

Cramer, F. (1936). Bull. neurol. Inst., N.Y., 5, 37.

Creutzfeldt, H. G. (1921). Arbeit ü. d. Grosshirnrinde (Nissl u. Alzheimer), p. 1.

Critchley, M. (1930). Proc. roy. Soc. Med., 23 (1), 533.

(1939). Cowdry's Problems of Ageing, p. 483. Baillière, Tindall and Cox, London. et al. (1932). Proc. roy. Soc. Med., 26 (2), 1077.

Dandy, W. E. (1928). J. Amer. med. Ass., 90, 823.

Davenport, C. B., and Muncey, E. B. (1916). Amer. J. Insanity, 73, 195.

Davison, C. (1932). Brain, 55, 247. (1938). Amer. J. Psychiat., 94, 801.

Dunlap, C. B. (1927). Arch. Neurol. Psychiat. Chicago, 18, 867.

Duus, P. (1939). Arch. Psychiat., 109, 596 (Abst. Arch. Neurol. Psychiat. Chicago, 43, 388).

Econor no, C. von, and Schilder, P. (1920). Z. ges. Neurol. Psychiat., 55, 1.

Evans, G. (1921). Quart. J. Med., 14, 215. (1924). Brit. med. J., 2, 1.

Farnel!, F. J., and Globus, J. H. (1932). Arch. Neurol. Psychiat. Chicago, 27, 593.

Ferrar', A. (1927). J. nerv. ment. Dis., 66, 329, 479, 616.

Ferraro, A., and Jervis, G. A. (1936). Arch. Neurol. Psychiat. Chicago, 36, 739.

Fickler, quoted by Wilson, S. A. K. Neurology, 1940, 2, 966.

Fischer, O. (1910). Z. ges. Neurol., Psychiat., 3, 371.

Fleischhacker, H. (1924). Ibid., 91, 1.

Frazier, C. H. (1936). Arch. Neurol. Psychiat. Chicago, 35, 525.

Freeman, W. (1933). Neuropathology, Philadelphia, p. 263.

Fuller, S. C. (1912). J. nerv. ment. Dis., 39, 440. 
Galbraith, A. J. (1940). J. ment. Sci., 86, 112.

Gans, A. (1923). Z. ges. Neurol. Psychiat., 80, 10.

Garrod, A. E. (1927). Lancet, 2, 1113.

Gerstmann, J., Straussler, E., and Scheinker, I. (1936). Z. ges. Neurol. Psychiat., $154,736$.

Globus, J. H. (1932). In Penfield's Cytology of the Nervous System, 3, 1145.

Goldstein, K., and Katz, S. E. (1937). Arch. Neurol. Psychiat. Chicago, 38, 473.

Golla, F. L. (1930). Proc. roy. Soc. Med., 24 (2), 1000.

Gowers, W. (1899). Lancet, 2, 1591. (1902). Ibid., 1, 1003.

Graves, R. J. (1848). Clinical Medicine (New Sydenham Society) 1884, 1, 48.

Greenfield, J. G. (1934). Brain, 57, 161.

(1938). Proc. roy. Soc. Med., 31, 1450.

Grünthal, E. (1922).

(1930). Bumke's Handbuch Geisteskrankh., 11, 638.

- (1935). Fortschr. Neurol. Psychiat., 7, 241.

(1936). Bumke and Foerster's Handbuch, 11, 466.

Guillain, G., and Bertrand, I. (1929). Rev. Neurol., 1, 577.

Gull, W. W., and Sutton, H. G. (1872). Med.-chir. Trans., 55, 273.

Gurewitsch, M. (1922). Z. ges. Neurol. Psychiat., 29, 249.

Hallervorden, J. (1930). Bumke's Handbuch Geisteskrankh., 11, 1086.

Hassin, G. B.(1933). Histopathology of the Peripheral and Central Nervous Systems. Baillière, Tindall and Cox, London.

Hastings, D. W. (1939). J. nerv. ment. Dis., 89, 44.

Heidenhain, A. (1928). Z. ges. Neurol. Psychiat., 118, 49.

Henderson, D. K., and Maclachlan, S. H. (1930). J. ment. Sci., 76, 646.

Holmes, G. (1930). Proc. roy. Soc. Med., 24 (2), 997.

Ironside, R., and Guttmacher, M. (1929). Brain, 52, 442.

Jakob, A. (1921). Z. ges. Neurol. Psychiat., 64, 147.

Jansen, J., and Monrad-Krohn, G. H. (1938). Ibid., 163, 670.

Jonesco-Sisesti, N., and Stroesco, M. G. (1939). Proc. 2nd Intern. Neurol. Congress, Copenhagen (Abst. Rev. Neurol., 72, 374).

Kehrer, F. (1921). Zbl. ges. Neurol. Psychiat., 25, 1.

King, L. S., and Meehan, M. C. (1936). Arch. Neurol. Psychiat, Chicago, 36, 547.

Kirschbaum, W. (1924). Z. ges. Neurol. Psychiat., 92, 175.

Krapf, E. (1931). Arch. Psychiat., Nervenkr., 93, 409.

Kufs, H. (1937). Ibid., 107, 431.

Lowenberg, K. (1937). Amer. J. Psychiat., 93, 757 (discussion following).

Lowenberg, K., Boyd, D. A., and Salon, D. D. (1939). Arch. Neurol. Psychiat, Chicago, 41. 1004.

Lowenberg, K., and Rothschild, D. (1931). Amer. J. Psychiat., 11, 269.

Lowenberg, K., and Waggoner, R. W. (1934). Arch. Neurol. Psychiat. Chicago, $31,737$.

McMenemey, W. H., and Pollak, E. Ibid., in press.

McMenemey, W. H., Worster-Drought, C., Flind, J., and Williams, H. G. (1939). J. Neurol. Psychiat., 2, 293.

MacNamara, E. D., and Dickson, W. E. C. (1932). Proc. roy. Soc. Med., 26 (1), 297.

Malamud, N., and Boyd, D. A. (1940). Arch. Neurol. Psychiat., Chicago, 43, 210.

Malamud, W., and Lowenberg, K. (1929). Ibid., 21, 805.

Marchand, L., Demay, G., and Naudascher, J. (1938). Ann. méd. psychol. 96 (2), 751.

Marie, P., Foix, C., and Alajouanine, T. (1922). Rev. Neurol., 38, 849, 1082.

Marinesco, G., and Draganesco, S. (1929). Encéphale, 24, 685.

Mathieu, P., and Bertrand, I. (1929). Rev. Neurol., 1, 721.

Mayer-Gross, W. (1938). Proc. roy. Soc. Med., 31, 1443.

Meggendorfer, F. (1926). Z. ges. Neurol. Psychiat., 101, 387.

Meggendorfer, F., and Stender, A. (1930). Ibid., 128, 337.

Merritt, H. H., and Fremont-Smith, F. (1937). The Cerebrospinal Fluid, Philadelphia.

Meyer, A., and Cook, L. C. (1937). J. ment. Sci., 83, 258.

Meyer, A., and Pilkington, F. (1936). Ibid., 82, 812.

Meyer, A., and Tennent, T. (1936). Brain, 59, 100.

Minski, L., and Guttmann, E. (1938). J. ment. Sci., 84, 21.

Morel, F. (1939). Rev. Neurol., 71, 280.

Mott, F. W. (1899). Lancet, 2, 1442.

-(1900). Ibid., 1, 1779, 1849.

Myerson, A. (1939). Amer. Res. nerv. ment. Dis., 19, 16.

Neuberger, quoted by Biggart (1936) (see above).

Neubürger, K., and Braunmühl, A. von (1930). Bumke's Handbuch Geisteskrankh., 11, 347.

Nichols, I. C., and Weigner, W. C. (1938). Brain, 61, 237.

Nielsen, J. M., and Raney, R. B. (1934). Bull. Los Angeles Neurol. Soc., 4, 1 (Abst. Arch. Neurol. Psychiat., Chicago, 1940, 43, 386.

Nikitin, M. (1925). Arch. Psychiat. Nervenkr., 75, 472. 
Onari, K., and Spatz, H. (1926). Z. ges. Neurol. Psychiat, 101, 470.

Parker, H. L., and Kernohan, J. W. (1933). Brain, 56, 191.

Penfield, W., and Evans, J. (1935). Ibid., 58, 115.

Perusini, G. (1910). Hist. u. Histopath. (Nissl u. Alzheimer), 3, 297.

Petersen, M. C. (1937). Amer. J. Psychiat., 94, 309.

Pickworth, F. A. (1934). J. Anat., 69, 62.

Powell, R. D. (1883). In Quain's Dictionary of Medicine.

Putnam, T. J. (1939). Amer. Res. nerv. ment. Dis., 19, 81.

Richter, R. (1940). J. nerv. ment. Dis., 91, 37.

Riddoch, G. (1936). Brain, 59, 225.

Rizzo, C. (1924). Riv. Patol. nerv. ment., 29, 482.

Rosenbach, quoted by Garrod, A. E. (see above).

Rothschild, D. (1934). Amer. J. Psychiat., 91, 485. (1937). Ibid., 93, 757. (1938). Ibid., 94, 801 (discussion following).

Rothschild, D., and Kasanin, J. (1936). Arch. Neurol. Psychiat., Chicago, 36, 293.

Rowe, S. N. (1937). Amer. J. Psychiat., 94, 605.

Runge, W. (1930). Bumke's Handbuch Geisteskrankh., 8, 542, 597.

Rủžičcka, V. (1922). Pflüg. Arch. f. Physiol., 194, 135. (1924). Roux Arch., 101, 459.

Sachs, E. (1930). Arch. Neurol. Psychiat. Chicago, 24, 735.

Savage, G. H. (1899). Lancet, $2,1592$.

Scheele, H. (1933). Z. ges. Neurol. Psychiat., 144, 606.

Schenk, V. W. D. (1938). Deuxième Congrès Hollando-Belge Neurol. Psychiat., 175.

Schneider, C. (1927). Mschr. Psychiat. Neurol., 65, 230.

Schottky, J. (1932). Z. ges. Neurol. Psychiat., 140, 333.

Schroeder, A. (1939). Ann. Fac. Med. Montevideo, 24, 421 (Abst. Lancet, 1939, 2, 1297).

Schroeder, A. H., and Kirschbaum, W. (1928). Z. ges. Neurol. Psychiat., 114, 681.

Smyth, G. E., and Stern, K. (1938). Brain, 61, 339.

Stern, K. (1938). J. Neurol. Psychiat, 1, 26. (1939). Brain, 62, 157.

Stertz, G. (1926). Z. ges. Neurol. Psychiat., $101,729$.

Stone, T. T., and Falstein, E. I. (1938). J. nerv. ment. Dis., 88, 602, 773.

Struwe, F. (1929). Z. ges. Neurol. Psychiat, 122, 291.

Symonds, C. P. (1930). Proc. roy. Soc. Med., 24 (2), 1007.

Thorpe, F. T. (1932). J. ment. Sci., 78, 302.

Urechia, C. I., and Danetz, C. (1924). Encéphale, 19, 382.

Vet, de, A. C. (1936). Over de Diagnostiek van het meningioma cerèbri, Amsterdam, p. 266.

Walshe, W. H. (1855). Med. Times and Gazette, 31, 613.

Weinberger, H. (1927). Z. ges. Neurol. Psychiat., 106, 666.

Wilson, S. A. K. (1931). Proc. roy. Soc. Med., 24 (2), 1008. (1940). Neurology. E. Arnold and Co., London.

Winkleman, N. W., and Moore, M. J. (1939). Arch. Neurol. Psychiat., Chicago, 41, 773.

Winslow, F. (1830). Lancet, 1, 36.

Worster-Drought, C. (1930). Proc. roy. Soc. Med., 24, (2), 1007.

Worster-Drought, C., and Allen, I. M. (1929). Brit. med. J., 2, 1149.

Worster-Drought, C., Greenfield, J. G., and McMenemey, W. H. (1940). Brain, 63, 237. 